\section{(2)}

\section{OPEN ACCESS}

\title{
(Not) talking about fertility: the role of digital technologies and health services in helping plan pregnancy. A qualitative study
}

\author{
Rebecca S French (1) , ${ }^{1}$ Jill Shawe, ${ }^{2}$ Nerissa Tilouche, ${ }^{1}$ Sarah Earle, ${ }^{3}$ \\ Pippa Grenfell ${ }^{1}$
}

\begin{abstract}
Department of Public Health Environments and Society, London School of Hygiene \& Tropical Medicine, London, UK ${ }^{2}$ School of Nursing and Midwifery, University of Plymouth, Plymouth, UK ${ }^{3}$ School of Health, Wellbeing and Social Care, The Open University, Milton Keynes, UK
\end{abstract}

\section{Correspondence to} Dr Rebecca S French, Public Health, Environments \& Society, London School of Hygiene \& Tropical Medicine, London, London, UK; Rebecca.French@ Ishtm.ac.uk

Received 8 September 2020 Revised 17 November 2020 Accepted 7 December 2020

\section{Check for updates}

(c) Author(s) (or their employer(s)) 2020. Re-use permitted under CC BY-NC. No commercial re-use. See rights and permissions. Published by BMJ.

To cite: French RS, Shawe J, Tilouche N, et al. BMJ Sex Reprod Health Published Online First: [please include Day Month Year]. doi:10.1136/ bmjsrh-2020-200862

\begin{abstract}
Aim To explore how women and their partners navigate (pre)conception healthcare and the role of Natural Cycles fertility awareness technology in this process.

Methods In-depth interviews with 24 cisgender women aged 24-43 years who had used Natural Cycles' 'Plan a Pregnancy' mode, and six partners of Natural Cycles users, all cisgender men aged 30-39 years. Participants were recruited via direct messaging in the Natural Cycles app, social media and, for partners, snowball sampling. Purposive sampling was conducted to ensure diversity among participants. Interviews were audio-recorded and transcribed verbatim. An iterative, inductive approach was adopted for thematic data analysis.
\end{abstract}

Results Natural Cycles helped most users better understand their menstrual cycles and fertility. Fertility awareness and preconception counselling with healthcare providers were uncommon. Women felt discussions about planning pregnancy in healthcare settings were often fraught with difficulties. They described not wanting to be an extra burden to overworked staff, being concerned that their worries about trying for pregnancy would be dismissed, or feeling staff did not have expertise in fertility awareness. Some women had shared their Natural Cycles data with healthcare professionals to demonstrate their menstrual cycle data or time of conception. However, it was not always clear to those not accessing services when they should seek further advice, for example, those using the app for longer time periods who had not yet conceived.

Conclusions Digital technologies can provide information and support for those wanting to conceive. They should, however, complement care in statutory services, and be accompanied by greater investment in fertility awareness and preconception support.

\section{Key messages}

- Limited time and lack of fertility awareness knowledge among health professionals were perceived as barriers to preconception discussions in healthcare settings.

- The use of Natural Cycles helped women (and their partners) better understand when they might best maximise their chances of conception.

- App developers should ensure signposting to relevant health services when users require further support or have not conceived within 12 months.

\section{BACKGROUND}

Fertility interventions have tended to target couples once they are having difficulties conceiving rather than pro-fertility initiatives being in place once the decision to have children has been made. ${ }^{12}$ Fertility declines with age; $92 \%$ of women aged 19-26 years trying for pregnancy conceive within 12 months compared with $82 \%$ of those aged $35-39$ years. If frequency of vaginal intercourse is once a week, these conception rates decline to $85 \%$ and $61 \%$, respectively. ${ }^{3}$ National Institute for Health and Care Excellence (NICE) guidelines recommend that opposite-sex couples wishing to conceive should have vaginal sex every 2 to 3 days to optimise their chances of pregnancy, and those using donor insemination should time the insemination around ovulation. ${ }^{4}$ Fertility awareness knowledge is low, with often limited understanding as to how timing of sexual intercourse affects chances of conception and overestimation of the time within the menstrual cycle 
when pregnancy can occur. ${ }^{5-8}$ Limited knowledge has also been found among healthcare providers. ${ }^{9}$ Short consultations and lack of training have been identified as barriers to fertility awareness counselling in general practice. ${ }^{10}$

A proliferation of fertility awareness and pregnancyrelated apps has provided users with greater autonomy, but has also led to closer monitoring of - and greater burden of - responsibility in managing their own fertility and health. ${ }^{11} 12$ Research on use of fertility awareness apps to support conception is sparse and concerns have been raised about the accuracy of many of the available apps in identifying the fertile window. ${ }^{13}$ Natural Cycles is a fertility awareness app for monitoring menstrual cycles, as a method of contraception or to aid conception. Users enter data on their cycle, basal body temperature (BBT) and, optionally, luteinising hormone urine test results. An algorithm, which allows for uncertainties in ovulation day prediction and pre- and post-ovulation temperatures, calculates the fertile window. A retrospective study conducted by the developers found the mean delay from the first positive ovulation test to the Natural Cycles estimation using BBT was $1.9( \pm 1.4 \mathrm{SD})$ days. ${ }^{14}$ This compares to a mean delay of $1.5( \pm 0.6 \mathrm{SD})$ days when using more precise ultrasound detection. ${ }^{15}$ Data on its contraceptive effectiveness have been published, ${ }^{16}$ but to date no such data have been published in relation to conception. The Freyja Study (https://www.lshtm. ac.uk/research/centres-projects-groups/freyja-study) used qualitative interviews to explore views and experiences of people using Natural Cycles to plan pregnancy. ${ }^{17}$ The aim of this article arising from the study is to explore how women and their partners navigate (pre)conception healthcare and the role of the Natural Cycles technology in this process.

\section{METHODS}

Women and partners were recruited via the Natural Cycles app and social media. Snowball sampling was also used to reach partners. Eligibility criteria included being aged between 18 and 44 years for women trying to conceive and $\geq 18$ years for partners, currently living in the UK, Natural Cycles experience in 'Plan' mode, ability to do the interview in English, and not having been advised to avoid pregnancy for health reasons. We used purposive and quota sampling to ensure representation of different users, including demographic characteristics and Natural Cycles usage, such as length of time using the app. Recruitment continued until no new themes emerged from the data, balanced against the project timeframe and resources.

Those individuals interested in participating were directed to the study website which included a questionnaire on demographic characteristics and Natural Cycles use to assess eligibility and aid purposive sampling. Participants were contacted by a researcher to schedule an interview over video-conferencing
Table 1 Characteristics of the Freyja Study participants

\begin{tabular}{lcl}
\hline Characteristic & $\begin{array}{l}\text { Women (n) } \\
(\mathbf{n}=\mathbf{2 4 )}\end{array}$ & Men (n) (n=6) \\
\hline Age group (years) & 1 & - \\
\hline 18-24 & 6 & - \\
\hline $25-29$ & 10 & 4 \\
\hline $30-34$ & 7 & 2 \\
\hline $35-39$ & 1 & - \\
\hline 40-44 & & \\
\hline Ethnicity & 3 & - \\
Asian/Asian British & 3 & - \\
\hline Black African/Caribbean/British & 16 & 6 \\
White British & 2 & - \\
White non-British & & \\
Income & & \\
\hline
\end{tabular}

Income

\begin{tabular}{lrc}
\hline Really comfortable/comfortable & 15 & 4 \\
\hline Neither comfortable or struggling & 6 & \\
\hline Struggling & 3 & \\
\hline Prior use of Natural Cycles for & 17 & NA
\end{tabular}
contraception

Duration of Natural Cycles in 'Plan' mode (months)

$<1$
$1-6$
$>6$

Pregnancy status at interview
$\begin{aligned} & \text { Currently pregnant } \\ & \text { Previous pregnancy but not }\end{aligned}$
currently
Has never been pregnant $\quad 10$

Not sure 1

NA, not asked.

software. A topic guide was used flexibly to follow participant narratives, and included use and experiences of health services prior to or while using the Natural Cycles app. All participants received a $£ 40$ voucher in recompense for their time. Interviews were audio-recorded, transcribed verbatim with participants' informed consent, and then anonymised. Pseudonyms are used in the reporting of results.

An iterative, inductive approach was adopted for analysis. ${ }^{18}$ Data were managed and coded using NVIVO 11 qualitative analysis software. More detailed Freyja Study methods have been published elsewhere. ${ }^{17}$

\section{RESULTS}

Twenty-four cis-women aged 24-43 years and six partners, all cis-men aged 30-39 years, were interviewed. One of the women interviewed had a female partner, all the others had male partners. table 1 summarises the participants' characteristics. 
Table 2 Themes and quotes

\section{Themes}

Accessing reliable information

\section{Consulting health services}

Challenges for new technologies in the delivery of fertility care

Role of fertility awareness technologies in the health service

\section{Quotes}

Q1 When you're younger you get drilled into you "... wear condoms, don't get pregnant, don't get pregnant".... It's like to scare you about pregnancy and then they scare you with like STDs and stuff like that but don't really educate you on the actual pregnancy thing. [Derek]

Q2... cervical fluid for example... like when you have really stretchy cervical mucus, obviously throughout my life I have had that, and had no idea what it was... But now for the first time in my life at the age of 30 I know what it is, which is, it's a bit sad really, I should have known before. [Hannah]

Q3 I've been to a gynaecologist and they've said that basal temperature is not the best way to record fertility and they've moved away from that a long time ago, which was slightly disconcerting... I said I was a bit surprised because I'd bought this app and it's medically certified and they use basal temperature, that's what I've been doing. [Helen]

Q4. She [the doctor] was just like, "Yeah, you just start trying and.... if you have any problems," I think like 6 months or something, "come back," ... no-one tells you like... should I try the day I come on my period? Should I try the day before I'm due on? Like they don't tell you anything about when you ovulate and stuff. [Amy]

Q5. I figured this[Natural Cycles] was a tool I could use to help me feel more in control and sort of get my own data because I wasn't really buying what I was hearing from the doctors... I trust my body at this point more than I trust the advice or input that I'm getting from my doctors... this is something that I'm doing for myself because I'm not being listened to. [Kara] Q6. The female said on the phone "Do you know how pregnant you are?" and I said "Ooh yes, I'm four plus one". She was like "Oh good grief, do you mind if I ask how do you know that?" I said "I've got an app". [Laughs]... she was really surprised that I could be that sure from an app. [Laura]

Q7 We're so desperate to start a family. When I was pregnant last October one of the things that popped up [n the app] and it scared the living daylights out of me was that if we see your temperature decreasing that could be the signs of an early miscarriage. [Emily]

Q8 There's a huge amount of limitation for what this [the app] can do .... and you're not using some other kind of human basis support to complement and supplement that data, are you possibly creating a difficult situation for yourself where you think something should be happening and you're not understanding why? [Samira]

Q9 I think it's something every woman should have like as standard and it should be just provided for free... supplied by things like the NHS services because it's what, an app and a thermometer? [Jessica]
Four broad themes were identified in the analysis for this article: accessing reliable information; consulting health services; challenges for new technologies in the delivery of fertility care; and the role of fertility awareness technologies in the health service. Longer quotes (Q) relating to themes are presented in table 2 and are cross-referenced in the text.

\section{Accessing reliable information}

Information about fertility in relationship and sex education (RSE) in schools and within the health service was described as lacking. Health promotion messages focused on prevention of pregnancy and sexually transmitted infections, which sometimes led to the belief that high fertility is a constant (Q1). For some, use of the Natural Cycles app was the first time they more fully understood how their or their partner's body was working in relation to fertility (Q2).

The internet, including websites and online fora, was usually the first port-of-call for information on planning pregnancy, where this information could be gathered privately and in one's own time. However, trying to find reliable evidence was described as "trawling through the white noise" (Laura) and it could be "lost in translation" (Megan). The National Health Service (NHS) website was the most commonly cited internet source, described as "fantastic" and "trusted", although a couple of women said they would have liked more information on the site. Many users had learnt about Natural Cycles through the internet or social media advertisements. Most had started using it to plan pregnancy without any consultation with healthcare providers.

\section{Consulting health services}

Knowledge of fertility awareness and associated apps among those working in primary care was generally perceived to be limited. A commonly reported reason women started using Natural Cycles as a contraceptive method was to avoid hormones, but also to 'get ready' and provide data for the app in preparation for switching to 'Plan a Pregnancy' mode. Natural 
family planning was rarely raised by practitioners as an option for either the prevention or planning of pregnancy, and some expressed frustration that doctors were committed to hormonal contraceptive methods.

A couple of women explained that their doctors had discredited fertility awareness methods to facilitate conception when they had shown them the app. Helen described feeling " a bit cheated", although she continued to log her data (Q3).

The general message women received from doctors was to come back in a year if they had not yet conceived. This was felt to be a missed opportunity for fertility advice (Q4). Kara, aged in her late thirties, was advised to have sex twice a week and to come back in a year if she was not pregnant. She felt that pinpointing the fertile window by using a fertility awareness app would be much better as she could ensure she was having sex at times to maximise her chances of conceiving. Use of Natural Cycles was a way of regaining control from doctors when women felt they were not being heard (Q5). Some interviewees used the app to demonstrate menstrual dates or gestation to healthcare staff visually or verbally (Q6).

Women variously described being "upset", "confused", and feeling like they were on a "conveyor belt" in their dealings with health services. Those with underlying health conditions identified challenges. Samantha, who thought she had polycystic ovary syndrome, described negative experiences trying to get specialist advice. Hannah, who had had early miscarriages, described only being given a leaflet on fertility awareness because of the time needed for counselling and lack of expertise at her general practice. Given anticipated or actual experiences within the health sector some participants described how it was just easier to do it themselves and not seek advice from doctors. They could become the experts of their own bodies: "it [Natural Cycles] was as scientific as I could get without having a lab in my house" [Kara].

For the most part, interviewees had not had any preconception discussions with healthcare providers. Their views were that the health sector would not be interested until they had been trying to conceive for over a year or were 12 weeks' pregnant. However, there were women who described positive preconception discussions with doctors, although the advice was still to wait a year before seeking any further investigations. A more integrated approach in consultations around menstrual health and the prevention and planning of pregnancy was also suggested.

\section{Challenges for new technologies in the delivery of fertility care}

While women described how digital health was a convenient way to understand and manage their fertility, apps were not without limitations. A concern raised was that apps do not indicate when one should seek further medical advice. This could be when conception had not yet occurred after a period of use, "When do you start getting worried... if it's not working?"' [Michelle], or if the data indicated any irregularities. Joanne had shown the temperature data to her reflexologist, who explained that her low BBT readings may be due to an underactive thyroid. Joanne felt that there could be alerts within the app when further medical advice should be sought: "I think it can leave you just feeling like 'Oh everything's fine', and for me it clearly isn't and yet the app doesn't tell me that". The fact that the app could detect early miscarriage led to anxiety (Q7). Some participants did acknowledge that fertility awareness apps should not be viewed as a replacement for 'human' support (Q8).

\section{Role of fertility awareness technologies in the health service}

Women's reproductive health was described as an underresourced area. Provision of fertility awareness apps was potentially a relatively inexpensive way of providing women with information about their bodies and helping them conceive (Q9).

Fertility awareness counselling required time for the initial consultation, and the fact that the NHS was already overstretched and staff were overworked was a common topic raised by participants. Interviewees described not wanting to burden the system or felt that their fertility queries or concerns would not be viewed as 'serious' enough. Offering women evidencebased fertility awareness apps via NHS practitioners or at least promoting them through posters in waiting rooms could be a way of addressing this issue. Participants noted that this would give such apps more "official standing, or it makes it a more trusted source" [Victoria]. Longer-term cost savings were also raised in relation to potential reductions in those accessing fertility treatments by using the app first.

Use of other private providers was mentioned by a few women, including complementary therapists such as acupuncturists and naturopaths, and private gynaecologists. Although most participants could easily afford $£ 40$ for the app (the retail price at the time of the interviews), it was acknowledged that this would not be the case for all women, and perhaps NHS funding, given the need to prioritise public resources, should be limited to those who could not afford it. Victoria said having to pay for the app ensured she was more dedicated to using it properly. However, Joanne noted that if women were taught properly, they could use a free app or paper and a thermometer, although she liked the well-designed technology and data visualisation in Natural Cycles.

\section{DISCUSSION}

This exploratory qualitative study found that using Natural Cycles helped women and their partners better understand their fertility. The internet was the first port of call for information and the NHS website 
was a trusted source. For most interviewees, fertility awareness and preconception counselling with healthcare providers was uncommon. Women felt discussions about planning pregnancy in healthcare settings were often fraught with difficulties, especially as staff were overworked and did not necessarily have the expertise or time to discuss fertility awareness. Some women had shared their Natural Cycles data with healthcare professionals to demonstrate their menstrual cycle data or time of conception. However, it was not always clear to those not accessing services when they should seek further advice, for example, those who had been using the app but had not yet conceived.

Health technologies that place responsibility on individuals to manage their health have been criticised for not attending to the broader contexts of users' lives. ${ }^{1920}$ Others argue that, with increased use of technology in real-world settings, the move away from biomedical authority to "expanded autonomy" and "ownership of one's body" is greater. ${ }^{21}$ However, while women may wish and/or experience pressure to be in command of their own fertility, such "expectations of choice and control are frequently an illusion". 22 We have reported elsewhere how Natural Cycles helped to break down some of the silences and taboos around fertility and menstruation, with the app facilitating conversations with friends and family. ${ }^{17}$ Yet, women often experienced difficulties navigating between use of digital technologies and health service cares, often due to lack of healthcare provider knowledge of fertility awareness methods and technologies, or their dismissal. This appeared to be more evident among the women who had difficulties conceiving or had other underlying health problems. While directto-consumer technologies can increase health literacy, provide personalised information and empower users with access to such technologies, better pathways between technologies and health services, and more communication about technologies in health services are needed. This will help to reduce user anxiety from overreliance and lack of communication and distrust between those using fertility awareness apps and healthcare providers. ${ }^{23}$

Calls have been made for better education about fertility in school RSE programmes and training for teachers and healthcare professionals. ${ }^{24}$ In our study, preconception discussions in primary care were not commonly reported, highlighting missed opportunities for health promotion and education. Women who receive preconception advice from health professionals prior to pregnancy are more likely to adopt healthier choices, such as taking folic acid or avoiding alcohol, before they become pregnant. ${ }^{25}$ Practice nurses' role in providing fertility awareness education and support within primary care is also underutilised. ${ }^{26}$ Furthermore, digital technology companies have opportunities to provide evidence-based health education and support, and have a responsibility to signpost users to mainstream services when further care or investigations may be required.

While mixed feelings among those interviewed on whether Natural Cycles should be freely available via the NHS were expressed, there was recognition that the cost of the app will be a barrier for some. Further research is needed to assess the the effectiveness and cost-effectiveness of Natural Cycles in relation to conception rates, as well as the time to conception. NICE recommends that women of reproductive age who have not conceived within 1 year and have no known cause of infertility should be offered clinical assessment and investigation with their partner. ${ }^{4}$ Access to NHS fertility treatment varies across the UK, and even where available there are long waiting lists. The personal and financial costs of fertility treatment are high. Fertility awareness technologies may offer a less costly option to try for those wanting to conceive prior to more invasive investigations.

Attempts were made in the sampling framework for this study to ensure representation of diversity among those interviewed. However, most participants were financially secure and had a high level of education, the latter being associated with increased fertility awareness knowledge. ${ }^{27}$ The findings may not be transferrable to those using other fertility awareness methods or to those trying to conceive. Most participants learnt about the study via direct messaging in the Natural Cycles app, and therefore we may have included those who were more engaged with the app, although some participants were no longer using the app regularly.

In times of growing financial pressures on primary care and sexual and reproductive health services, digital technologies can provide access to information and support to help those wanting to conceive. They should, however, complement care in statutory services, and be accompanied by greater investment in fertility awareness and care.

Acknowledgements The authors would like to thank everyone who participated in interviews and/or expressed interest in the Freyja Study, for their time and the valuable information they shared. They also wish to thank the study steering group, Dr Sarah Earle, Ms Suzanne Basnett and Dr Sesh Sunkara, for insightful advice and comments throughout the project. They are grateful to Dr Simon Rowland and Dr Jack Pearson for liaising with the Natural Cycles app team to post the study advertisement. They also wish to acknowledge and thank Natural Cycles for their financial support of this study.

Contributors RSF, PG, NT and JS conceived the idea for the research, developed the methods, conducted interviews and planned analysis. SE advised on the methodology and the conduct and interpretation of the analysis. RSF drafted the article with input from all authors. All the authors approved the final draft.

Funding This study was undertaken with funding from Natural Cycles. The funder had no involvement in study design, data collection, analysis or interpretation, including the decision to publish. The views expressed in this publication are those of the authors and not necessarily those of Natural Cycles. 
Competing interests None of the authors have any involvement in Natural Cycles and they did not receive any financial or other incentive to conduct this research other than their usual university salaries. Before developing the Freyja proposal, RSF and JS received an honorarium from Natural Cycles to participate in an expert workshop aimed at identifying research gaps in relation to fertility awareness methods.

Patient and public involvement Patients and/or the public were involved in the design, or conduct, or reporting, or dissemination plans of this research. Refer to the Methods section for further details. Ms Suzanne Basnett was the lay member of the Study Advisory Group. She provided advice on participant recruitment, the interview topic guide and interpretation of results. She also advised on dissemination strategies to ensure that the study's findings would be accessible to all.

Patient consent for publication Not required.

Ethics approval This study received favourable ethical opinion from the London School of Hygiene and 159 Tropical Medicine Ethics Committee (Ref: 16141).

Data availability statement No data are available.

Open access This is an open access article distributed in accordance with the Creative Commons Attribution Non Commercial (CC BY-NC 4.0) license, which permits others to distribute, remix, adapt, build upon this work noncommercially, and license their derivative works on different terms, provided the original work is properly cited, appropriate credit is given, any changes made indicated, and the use is noncommercial. See: http://creativecommons.org/licenses/by-nc/4. $0 /$.

\section{ORCID iD}

Rebecca S French http://orcid.org/0000-0002-1962-5022

\section{REFERENCES}

1 Shawe J, Mann S, Stephenson J. The move to integrated contraception and sexual health services: have we forgotten family 'planning'? J Fam Plann Reprod Health Care 2009;35:250-3.

2 Hvidman HW, Petersen KB, Larsen EC, et al. Individual fertility assessment and pro-fertility counselling; should this be offered to women and men of reproductive age? Hum Reprod 2015;30:9-15.

3 Dunson DB, Baird DD, Colombo B. Increased infertility with age in men and women. Obstet Gynecol 2004;103:51-6.

4 National Institute for Health and Care Excellence (NICE). Fertility: assessment and treatment for people with fertility problems, 2013. Available: https://www.nice.org.uk/guidance/ cg156/evidence/full-guideline-pdf-188539453 [Accessed 30 Oct 2019].

5 Practice Committee of the American Society for Reproductive Medicine in collaboration with the Society for Reproductive Endocrinology and Infertility. Optimizing natural fertility: a Committee opinion. Fertil Steril 2017;107:52-8.

6 Peterson BD, Pirritano M, Tucker L, et al. Fertility awareness and parenting attitudes among American male and female undergraduate university students. Hum Reprod 2012;27:1375-82.

7 Hampton KD, Mazza D, Newton JM. Fertility-awareness knowledge, attitudes, and practices of women seeking fertility assistance. J Adv Nurs 2013;69:1076-84.

8 Hammarberg K, Setter T, Norman RJ, et al. Knowledge about factors that influence fertility among Australians of reproductive age: a population-based survey. Fertil Steril 2013;99:502-7.
9 García D, Vassena R, Prat A, et al. Poor knowledge of agerelated fertility decline and assisted reproduction among healthcare professionals. Reprod Biomed Online 2017;34:327.

10 Hampton KD, Newton JM, Parker R, et al. A qualitative study of the barriers and enablers to fertility-awareness education in general practice. J Adv Nurs 2016;72:1541-51.

11 Lupton D. 'Mastering your fertility': the digitised reproductive citizen. In: McCosker A, Vivienne S, Johns A, eds. Negotiating digital citizenship: control, contest and culture. London: Rowman and Littlefield, 2015.

12 Lupton D. Quantified sex: a critical analysis of sexual and reproductive self-tracking using apps. Cult Health Sex 2015;17:440-53.

13 Earle S, Marston HR, Hadley R, et al. Use of menstruation and fertility app trackers: a scoping review of the evidence. BMJ Sex Reprod Health 2020. doi:10.1136/bmjsrh-2019-200488. [Epub ahead of print: 06 Apr 2020].

14 Berglund Scherwitzl E, Lindén Hirschberg A, Scherwitzl R. Identification and prediction of the fertile window using NaturalCycles. Eur J Contracept Reprod Health Care 2015;20:403-8.

15 Behre HM, Kuhlage J, Gassner C, et al. Prediction of ovulation by urinary hormone measurements with the home use ClearPlan Fertility Monitor: comparison with transvaginal ultrasound scans and serum hormone measurements. Hum Reprod 2000;15:2478-82.

16 Berglund Scherwitzl E, Gemzell Danielsson K, Sellberg JA, et al. Fertility awareness-based mobile application for contraception. Eur J Contracept Reprod Health Care 2016;21:234-41.

17 Grenfell P, Tilouche N, Shawe J, et al. Women and partners' narratives of using the fertility mobile app 'Natural Cycles' while trying to conceive. Sociol Illn Health 2020;4.

18 Charmaz K. Grounded theory. In: Smith JA, ed. Qualitative psychology: a practical guide to research methods. 2nd Edition. London: Sage, 2008.

19 Johnson S. "Maternal devices", social media and the selfmanagement of pregnancy, mothering and child health. Societies 2014;4:330-50.

20 Krüsi A, McNeil R, Moore D, et al. 'Because I've been extremely careful': HIV seroconversion, responsibility, citizenship and the neo-liberal drug-using subject. Health Risk Soc 2017; 19:58-73.

21 Dennison L, Morrison L, Conway G, et al. Opportunities and challenges for smartphone applications in supporting health behavior change: qualitative study. J Med Internet Res 2013;15:e86.

22 Earle S, Letherby G. Whose choice is it anyway? Decision making, control and conception. Hum Fertil 2002;5:39-41.

23 Ho A, Quick O. Leaving patients to their own devices? Smart technology, safety and therapeutic relationships. BMC Med Ethics 2018;19:18.

24 Harper J, Boivin J, O'Neill HC, et al. The need to improve fertility awareness. Reprod Biomed Soc Online 2017;4:18-20.

25 Stephenson J, Patel D, Barrett G, et al. How do women prepare for pregnancy? Preconception experiences of women attending antenatal services and views of health professionals. PLoS One 2014;9:e103085.

26 Ojukwu O, Patel D, Stephenson J, et al. General practitioners' knowledge, attitudes and views of providing preconception care: a qualitative investigation. Ups J Med Sci 2016;121:25663. 
